\title{
Bacteriological profile and antibiotic sensitivity pattern of neonatal sepsis in a tertiary care hospital of northern India
}

\author{
Bhat M. ${ }^{1}$, Saini G.S. ${ }^{2}$ \\ ${ }^{1}$ Dr. Minakshi Bhat, Lecturer, Pediatrics, Terna Medical College, Nerul, Navimumbai, ${ }^{2}$ Dr. G.S. Saini, Professor, \\ Pediatrics, SMGS Hospital, Government Medical College, Jammu, India.
}

Address for Correspondence: Dr. Minakshi Bhat, Lecturer department of Pediatrics, Terna Medical College, Nerul, Navimumbai. Emal Id: minakshi_libra@yahoo.in

\begin{abstract}
Introduction: Neonatal sepsis is the single most important cause of neonatal deaths in the community. Objectives: To identify the common bacterial pathogens associated with neonatal sepsis and to identify their antibiotic sensitivity pattern. Material and Methods: During the study period, all the neonates admitted in neonatology ward were screened for sepsis by physical examination and clinical features. All infants satisfying the criteria for sepsis were subjected for blood culture. Growths, if any were noted and standard antibiotic sensitivity was performed by the Kirby-Bauer disc diffusion method as per the CLSI recommendations. Results: Out of 2520 neonates admitted in neonatal intensive care unit over a period of one year, 89 neonates were diagnosed as having septicemia. Incidence of sepsis in our hospital was $35.3 / 1000$ neonatal admissions. Out of 89 clinically suspected and positive screening test cases of neonatal sepsis, $48.31 \%$ were culture proven cases of neonatal sepsis. Klebsiella was found to be the predominant pathogen (34.88\%) of the culture positive cases followed by staphylococcus aureus in $32.5 \%$ and E. coli in $9.30 \%$ cases. Majority of the organisms were resistant to commonly used antibiotics like ampicillin, cloxacillin and ceftriaxone. Aminoglycosides were relatively more effective treatment modalities against gram negative organisms while vancomycin was the most sensitive drug against Staphy lococcus aureus. Conclusions: In view of growing bacterial resistance to commonly used antibiotics, knowledge of bacterial pathogens prevalent in NICU and their antimicrobial susceptibility pattern will help the clinician to select appropriate antibiotics for treatment of suspected neonatal sepsis cases.
\end{abstract}

Keyword: Incidence, Neonatal sepsis, Bacterial isolates, Antibiotic susceptibility pattern, Gram-positive, Gram-negative.

\section{Introduction}

Neonatal sepsis is a significant cause of morbidity and mortality among neonates Worldwide [1,2,3,4]. The overall incidence of culture proven sepsis varies between 1-8 cases per 1000 live births with equal distribution of early and late onset cases [5,6,7,8]. Neonatal sepsis can be divided into two sub-types depending upon whether the onset of symptoms is before 72 hours of life [early onset sepsis (EOS)] or later [late onset sepsis (LOS)]. Early-onset infections are caused by organisms prevalent in the maternal genital tract or in the delivery area. Late- onset septicemia is caused by the organisms thriving in the external environments of the home or the hospital [9]. The organisms commonly associated with EOS are group B streptococcus and E coli in the west, while in

Manuscript received: $24^{\text {th }}$ October 2016

Reviewed: $5^{\text {th }}$ November 2016

Author Corrected; $20^{\text {th }}$ November 2016

Accepted for Publication: $30^{\text {th }}$ November 2016
India most cases are due to Gram- negative organisms especially E. coli, klebsiella, and enterobacter sp. $[10,11]$. Organisms that have been implicated in LOS are coagulase-negative Staphylococci (CONS), Staphylococcus aureus, Klebsiella pneumoniae, Escherichia coli, Enterobacter spp., Pseudomonas aeruginosa and anaerobes [11,12]. Prompt diagnosis and effective treatment is necessary to prevent deaths and complications due to septicemia. The blood culture remains the "Gold Standard" for the diagnosis for neonatal sepsis though its sensitivity is $50-80$ percent [12]. But the results of blood culture takes hours to days, thus necessitating initial empirical treatment of suspected cases. Hence, the current study was designed to determine the common bacterial agents associated with neonatal sepsis and their antibiotic susceptibility pattern in a tertiary care hospital in Northern India. 


\section{Materials and Methods}

Study setting and duration- This prospective observational cohort study was conducted in the department of Paediatrics SMGS Hospital, in collaboration with the department of microbiology, Government Medical College Jammu over a period of one year from December 2014 through November 2015. Prior approval was obtained from the Research and Ethical committee of our institute and informed consent was obtained from each patient's next of kin. During the study period, A total of 2520 neonates admitted in neonatal intensive care unit (NICU) were screened for sepsis by the examining physician and sepsis was clinically suspected if the neonate had symptoms and signs suggestive of sepsis such as poor feeding, poor activity, respiratory distress, apnea, seizure, lethargy, bulging anterior fontanel, fever, hypothermia, jaundice, vomiting, loose stools, abdominal distension, cyanosis, bleeding, mottling, tachycardia, weak pulse, grunting, retractions, nasal flaring were noted. Septic screening tests like band cell count, $\mathrm{C}$ - reactive protein, and micro erythrocyte sedimentation rate were done in all cases. All neonates in whom sepsis was suspected and had at least two positive screening tests were included in the study. All blood cultures were collected from a peripheral vein under all aseptic precautions before starting any antibiotic therapy. A minimum $1.5 \mathrm{ml}$ of blood was collected from each patient using proper aseptic precautions and inoculated immediately into 30 $\mathrm{mL}$ of Tryptic soya broth (Hi -Media Laboratories, Mumbai). The bottles were incubated aerobically at $37^{\circ} \mathrm{C}$ for 24 hours. Subcultures were made on sheep blood agar, MacConkey agar and chocolate agar routinely after 48 hours and 7 days. All the inoculated culture plates were incubated at $37^{\circ} \mathrm{C}$ for overnight. After incubation, the growth was identified by colony characteristics and standard biochemical tests. Antibiotic sensitivity was tested by the Kirby-Bauer disc diffusion method as per the CLSI recommendations (NCCLS Supplement 2000) for routinely used antibiotics like ampicillin, cloxacillin, gentamycin, chloramphenicol, amikacin, netlmycin, ceftriaxone, ciprofloxacin and vancomycin.

Statistical Analysis- Data were coded and entered into MS-Excel sheet. Statistical analysis were done using software SPSS 20 version. Descriptive and inferential statistics were used. Data were presented in percentages and simple bar diagram.

\section{Results}

During study period 2520 neonates were admitted in the NICU. Out of them 89 neonates were diagnosed as having septicemia. Incidence of neonatal sepsis in our hospital in the present study was 35.5/1000 neonatal admissions. Blood culture was positive in $43(48.3 \%)$ neonates with sepsis. Bacteriological profile of 43 septicemic neonates with positive blood cultures is shown in table No.1.

Table-1: Bacteriological profile of 43 septicemia neonates with positive blood cultures.

\begin{tabular}{|c|c|c|c|}
\hline Organism & $\begin{array}{c}\text { Total } \\
(\mathbf{n = 4 3 )}\end{array}$ & $\begin{array}{c}\text { EOS } \\
(\mathbf{n = 2 5})\end{array}$ & $\begin{array}{c}\text { LOS } \\
(\mathbf{n}=\mathbf{1 8})\end{array}$ \\
\hline klebsiella & $15(34.88 \%)$ & $8(32 \%)$ & $7(38.9 \%)$ \\
\hline Staphylococcus aureus & $14(32.5 \%)$ & $8(32 \%)$ & $6(33.3 \%)$ \\
\hline E. coli & $4(9.30 \%)$ & $3(12 \%)$ & $2(11.1 \%)$ \\
\hline Citrobacter & $4(9.30 \%)$ & $2(8 \%)$ & - \\
\hline Enterobacter & $2(4.65 \%)$ & $2(8 \%)$ & $1(5.6 \%)$ \\
\hline Aerobic spore bearer & $2(4.65 \% 0$ & $1(4 \%)$ & - \\
\hline Salmonella species & $1(2.32 \%)$ & $1(4 \%)$ & $1(5.6 \%)$ \\
\hline Candida & $1(2.32 \% 0$ & - & \\
\hline
\end{tabular}

(Figures in brackets indicate percentages)

Out of culture proven cases, 28 (65.11\%) sepsis cases were attributable to gram negative species while only14 (32.6\%) cases were attributable to gram positive. Klebsiella was the commonest organism isolated in $15(34.88 \%)$ neonates \& Staphylococcus aureus in 14(32.5\%). Klebsiella was the commonest organism isolated in both early onset (32\%) and late onset sepsis (38.9\%) followed by Staphylococcus aureus (32\% EOS and 33.3\% LOS respectively). Bacterial isolates and their sensitivity to various antibiotics is shown in table no.2. Klebsiella isolates were sensitivity to netilmycin (60\%), 
amikacin (53.3\%), ciprofloxacin (53.3\%), Ceftriaxone (46.7\%), chloramphenicol (33.3\%), gentamycin $(26.7 \%)$, and ampicillin (13.3\%). Staphylococcus was sensitive to vancomycin in $71.5 \%$ cases followed by amikacin, netilmycin $(50 \%$ each) and Gentamycin (28.8\%). Thus the aminoglycosides had good sensitivity for both gram positive and gram negative organisms while most of the organisms showed resistance to commonly used drugs like ampicillin, cloxacillin and ceftriaxone.

Table-2: Bacterial isolates and their sensitivity pattern to various antibiotics.

\begin{tabular}{|c|c|c|c|c|c|c|c|c|c|}
\hline Organism & Amp. & Clox. & Chlor. & Genta. & Amik. & Netil. & Ceft. & Cipro. & Vanco. \\
\hline Klebsiella & $\begin{array}{c}2 \\
(13.3)\end{array}$ & - & $\begin{array}{c}5 \\
(33.3)\end{array}$ & $\begin{array}{c}4 \\
(26.7)\end{array}$ & $\begin{array}{c}8 \\
(53.3)\end{array}$ & $\begin{array}{c}9 \\
(60)\end{array}$ & $\begin{array}{c}7 \\
(46.7)\end{array}$ & $\begin{array}{c}8 \\
(53.3)\end{array}$ & - \\
\hline $\begin{array}{c}\text { Staphylococcus } \\
\text { aureus }\end{array}$ & $\begin{array}{c}3 \\
(21.4)\end{array}$ & $\begin{array}{c}3 \\
(21.4)\end{array}$ & $\begin{array}{c}1 \\
(7.1)\end{array}$ & $\begin{array}{c}4 \\
(28.6)\end{array}$ & $\begin{array}{c}7 \\
(50)\end{array}$ & $\begin{array}{c}7 \\
(50)\end{array}$ & $\begin{array}{c}3 \\
(21.4)\end{array}$ & $\begin{array}{c}2 \\
(14.2)\end{array}$ & $\begin{array}{c}10 \\
(71.4)\end{array}$ \\
\hline E. coli & $\begin{array}{c}1 \\
(25)\end{array}$ & - & $\begin{array}{c}3 \\
(75)\end{array}$ & $\begin{array}{c}3 \\
(75)\end{array}$ & $\begin{array}{c}2 \\
(50)\end{array}$ & $\begin{array}{c}3 \\
(75)\end{array}$ & $\begin{array}{c}1 \\
(25)\end{array}$ & $\begin{array}{c}1 \\
(25)\end{array}$ & - \\
\hline Citrobacter & $\begin{array}{c}1 \\
(25)\end{array}$ & - & $\begin{array}{c}2 \\
(50)\end{array}$ & $\begin{array}{c}2 \\
(50)\end{array}$ & $\begin{array}{c}2 \\
(50)\end{array}$ & $\begin{array}{c}2 \\
(50)\end{array}$ & $\begin{array}{c}2 \\
(50)\end{array}$ & $\begin{array}{c}2 \\
(50)\end{array}$ & - \\
\hline Enterobacter & - & - & $\begin{array}{c}2 \\
(100)\end{array}$ & $\begin{array}{c}1 \\
(50)\end{array}$ & $\begin{array}{c}1 \\
(50)\end{array}$ & $\begin{array}{c}1 \\
(50)\end{array}$ & $\begin{array}{c}2 \\
(100)\end{array}$ & - & - \\
\hline $\begin{array}{l}\text { Salmonella } \\
\text { species }\end{array}$ & - & - & - & $\begin{array}{c}1 \\
(100)\end{array}$ & $\begin{array}{c}1 \\
(100)\end{array}$ & $\begin{array}{c}1 \\
(100)\end{array}$ & - & $\begin{array}{c}1 \\
(100)\end{array}$ & - \\
\hline
\end{tabular}

(Figures in brackets indicate percentages)

Amp.=Ampicillin,Clox. $=$ Cloxacillin,Chlor. $=$ Chloramphenicol,Genta. $=$ Gentamycin,Amik. $=$ Amikacin,Netil. $=$ Netilm ycin,Ceft. $=$ Ceftriaxone,Cipro. $=$ Ciprofloxacin,Vanco. $=$ Vancomycin

\section{Discussion}

Neonatal sepsis refers to systemic and generalized bacterial infection of the newborn documented by a positive blood culture in the first four weeks of life and is one of the four leading causes of neonatal mortality in India [13]. The gold standard for diagnosis of septicemia is the isolation of bacterial agent from blood culture. The prevalence of bacterial profile of blood culture and their susceptibility patterns in an area, provide guidance to start empirical treatment which is the cornerstone in the management of sepsis [13]. In this study, the incidence of neonatal sepsis was $35.3 / 1000$ neonatal admissions which is consistent with studies done by Chacko et a [5], National Neonatal, Perinatal Database [14] and Sharma et al [15]. In our study the blood culture positivity rate in neonatal sepsis cases was $48.3 \%$, similar results were observed by Chacko et al [5].

However some studies have reported higher blood culture positivity rates $[15,16]$. Also, the gram negative organisms constituted the major group of isolates $(65.11 \%)$ from neonatal septicemia cases, which correlates with the findings $(67.85 \%)$ of Desai et al.[17] and another study [13]. Klebsiella was the predominant pathogen of neonatal sepsis in our study (34.9\%) followed by Staphylococcus aureus (32.5\%) and E coli (9\%) which correlates with the observations made by
Deorari, and National Neonatal Perinatal Database $[1,18,19]$. These observations were different from that reported by Karthikeyan et al [20] wherein Staphylococcus aureus was the predominant pathogen $(61.5 \%)$ followed by Klebsiella $(21.9 \%)$ and E. col $(13.5 \%)$ The results of antibiotic sensitivity revealed that majority of the organisms were resistant to commonly used antibiotic like ampicillin, cloxacillin and ceftriaxone. It has been also shown that aminoglycosides like netilmycin, amikacin and gentamycin were most effective antibiotics against gram negative organisms and also were effective against Staphylococcus aureus. But vancomycin still remains the most sensitive drug for Staphylococcus aureus. Similar results were also reported in studies conducted by Mathur et al, Khatua et al, and Tallur et al $[2,16,21]$.

\section{Conclusion}

Incidence of neonatal sepsis in our study was 35.3/1000 neonatal admissions. Klebsiella, Staphylococcus aureus and $\mathrm{E}$ coli are the most common organisms causing neonatal sepsis. Both gram-positive and gram-negative bacteria have developed resistance against commonly used antibiotics like ampicillin, cloxacillin and ceftriaxone. Aminoglycosides are relatively more effective treatment modalities. 
Acknowledgements: we sincerely thank Mrs. Janish Raina, laboratory technician for her help and coordination.

Contribution: Dr. Minakshi Bhat: Designing and drafting of the manuscript. Dr. G. S. Saini : Final approval of the manuscript

\section{Funding: Nil, Conflict of interest: Nil \\ Permission from IRB: Yes}

\section{References}

1. Deorari AK. Changing pattern of bacteriological profile in neonatal sepsis among intramral babies.J Neonatol 2006;20(1):8-1.

2. Mathur NB, khalil A, Sarkar R, Puri RK. Mortality in neonatal septicemia with involvement of mother in management. Indian Pediatr1991;28:1259-1263.

3. Mathur NB , Singh A, Sharma VK, Satya narayana L.Evaluation of risk factors for fatal neonatal sepsis. Indian Pediatr 1996;33:817-22.

4. Ohlsson A, Bailey T, Takieddine F. Changing etiology and outcome of neonatal septicemia in Riyadh, Saudi Arabia. Acta Pediatr Scand 1986;75 (4): $540-544$.

5. Chacko B, Sohi I.Early onset neonatal sepsis. Indian J Pediatr 2005;72:23-6.

6. Chawla D,Agarwal R. Rational approach to diagnosis of neonatal sepsis.J Neonatol 2006;20(1):4-7.

7. Choudhury VP, Fazel MI, Choudhury M, Ghafary A. Neonatal infections and their outcome in Afghanistan. Indian Pediatr1987;24:1019-25.

8. Choudhury VP, Srivastava G, Aggarwal DS et al. Bacteriological study of neonatal infection.Indian Pediatr 1975;22:459-472.

9. Zaidi AK, Thaver D, Ali SA, Khan TA. Pathogens associated with sepsis in newborns and young infants in developing countries. Pediatr Infect Dis J. 2009 Jan; 28 (1Suppl):S10-8. doi: 10.1097/INF. 0b013e 3181958769.
10. Datta S, Oberoi JK, Chugh TD. Laboratory diagnosis of neonatal sepsis. J Neonatol 2006; 20 (1): $16-23$

11. Niduvaje K, Amutha C, Roy J. Early neonatal streptococcal infection. Indian J Pediatr2006;73:573-6.

12. Singh M. Neonatal septicemia. In: Care of the Newborn, 6th Edn, Sagar Publications, New Delhi 2004: 209-216.

13. Mustafa M, Laeeq Ahmed S. Bacteriological profile and antibiotic susceptibility patterns in neonatal septicemia in view of emerging drug resistance. J. Med. Allied Sci.2014; 4(1): 2-8.

14. Report of the Natonal Neonatal Perinatal Database (National Neonatology Forum) 2000.

15. Sharma PP, Halder D, Dutta AK et al. Bactriological profile of neonatal septicemia. Indian Pediatr 1987; 24: 1011-17.

16. $\mathrm{K}$ hatua SP, Das AK, Chatterjee BD et al. Neonatal septicemia. I ndian J Pediatr1986;53:509-14.

17. Desai, K.J, Malek S.S, Parikh, A. 2011. Bacterial isolates and their antibiotics susceptibility patterns. Gujarat Med. J 2011; 66(1): 13-15.

18. Neonatal morbidity and mortality: Report of the National Neonatal Perinatal Database. Indian Pediatr 1997;34:1039-42.

19. Neonatal morbidity and mortality: Report of the National Neonatal Perinatal Database. Indian Pediatr $1999 ; 36: 167-9$.

20. Karthikeyan G, Premkumar K. Neonatal sepsis: Staphylococcus areus as the predominant pathogen. Indian J Pediatr $2001 ; 68: 715-7$.

21. Tallur SS, Kasturi AV, Nadgir SD, Krishna BV. Clinico-bacteriological study of neonatal septicemia in Hubli. Indian J Pediatr 2000; 67 :169-74.

\section{How to cite this article?}

Bhat M, Saini G.S. Bacteriological profile and antibiotic sensitivity pattern of neonatal sepsis in a tertiary care hospital of northern India.Int.J Pediatr Res.2016;3(11):831-834.doi:10.17511/ijpr.2016.i11.11. 